* Graduando em Direito pela Universidade do Estado do Amazonas. Estagiário do Fórum de Justiça da Comarca de Tabatinga. Contado: gdsf.dir@gmail.com.

**Graduado em Direito pela Universidade do Estado do Amazonas. Advogado. Graduado em Administração e Ciências Contábeis pela Universidade Federal do Amazonas. Mestre em Gestão de Áreas Protegidas da Amazônia pelo Instituto Nacional de Pesquisa da Amazônia. Mestre em Direito Ambiental pelo Programa de PósGraduação em Direito Ambiental da Universidade do Estado do Amazonas (PPGDA-UEA). Doutor em Geografia pela Universidade Federal de Goiás. Doutorando pelo Programa de Pós-Graduação em Direito da Universidade Federal do Estado de Minas Gerias (PPGDUFMG). Professor Permanente da Universidade do Estado do Amazonas (UEA). Contato: ysilva@uea.edu.br

*** Graduado em Direito pela Universidade da Amazônia. Advogado. Mestre em Direito Ambiental pelo Programa de Pós-Graduação em Direito Ambiental da Universidade do Estado do Amazonas (PPGDAUEA). Professor Permanente da Universidade do Estado do Amazonas (UEA). Doutorando pelo Programa de Pós-Graduação em Direito da Universidade Federal do Estado de Minas Gerias (PPGDUFMG). Coordenador da Clínica de Mecanismos de Soluções de Conflitos (MArbiC-UEA). Link do Lattes: http://lattes.cnpq. br/9956374214863816 ORCID: https://orcid.org/0000-0001-59034203 Contato: denisonaguiarx@ hotmail.com.

\section{Violação Ao Princípio do Mínimo Existencial Ecológico Na Inexistência De Plano Nacional De RESíduOs Sólidos}

\author{
Violation To The Principle Of The Ecological \\ Existential Minimum In The Next National Solid \\ WASTE Plan
}

\author{
Guilherme da Silva Farias* \\ Ygor Felipe Távora da Silva** \\ Denison Melo de Aguiar***
}

Como citar: FARIAS, Guilherme da Silva; SILVA, Ygor Felipe Távora da; AGUIAR, Denilson Melo de. Violação do princípio do mínimo existencial ecológico na inexistência de plano nacional de resíduos sólidos. Revista do Instituto de Direito Constitucional e Cidadania - IDCC, Londrina, v. 5, n. 1, p 169186, jan/jul, 2020. ISSN: 2596-0075.

https://doi.org/10.48159/revistadoidcc.v5n1.farias.silva.aguiar

Resumo: As implicações da ausência de um Plano Nacional de Resíduos Sólidos no atingimento de meta instituída na Política Nacional de Políticas Públicas de eliminação e recuperação dos lixões no país, são violações ao princípio do mínimo existencial ecológico. O objetivo desta pesquisa é demonstrar que a ausência de um Plano Nacional de Resíduos Sólidos possui implicações no atingimento das metas de eliminação e recuperação dos lixões, bem como interferem na violação do princípio ao mínimo existencial ecológico. Utilizou-se a pesquisa indutiva e qualitativa, com técnicas de levantamento teórico-bibliográfico em leis, doutrinas e jurisprudências, em especial com pesquisa em artigos científicos. A violação do princípio do mínio existencial pela inexistência do Plano Nacional de Resíduos Sólidos.

Palavras-chave: Princípio do Mínimo Existencial Ecológico. Plano Nacional de Resíduos Sólidos. Plano de Manejo. Plano de Gestão Integrada.

Abstract: The implications of the absence of a National Solid
Waste Plan in reaching the goal established in the National
Policy of Public Policies for the disposal and recovery of dumps
in the country, are violations of the principle of ecological
minimum existential. The objective of this research is to
demonstrate that the absence of a National Solid Waste Plan has
implications for achieving the goals of disposal and recovery of 
dumps, as well as interfering with the violation of the principle of ecological existential minimum. Inductive and qualitative research was used, with theoretical-bibliographic survey techniques in laws, doctrines and jurisprudence, especially with research in scientific articles. Violation of the principle of existential domination by the inexistence of the National Solid Waste Plan.

Keywords: Principle of Ecological Existential Minimum. National Solid Waste Plan. Management Plan. Integrated Management Plan. 


\section{INTRODUÇÃO}

A Lei ${ }^{\circ}$ 12.305/2010 (BRASIL, 2010), que instituiu a Política Nacional de Resíduos Sólidos (PNRS), constitui-se em instrumento essencial na busca de soluções para um dos mais graves problemas ambientais do Brasil, o mal destino dado aos resíduos sólidos, impondo a necessidade premente de substituir os lixões a céu aberto por aterros sanitários como medida de proteção ambiental.

A Política Nacional de Resíduos Sólidos, em seu art. 15, determina que a União elaborará o Plano Nacional de Resíduos Sólidos, com vigência por prazo indeterminado e horizonte de 20 (vinte) anos, a ser atualizado a cada 4 (quatro) anos. O prazo para elaboração do plano encerrou em agosto de 2012, mas ainda se encontra em versão preliminar desde 2011 (BRASIL, 2010).

Por se tratar de uma questão que, aparentemente, aflige apenas os moradores do local onde estão situados os lixões, acaba-se por atribuir a responsabilidade pelo não cumprimento das metas ao Estado ou Município. Olvida-se que a participação da União é fundamental, em ordem hierárquica e de planejamento para que os planos e as estratégias de todos os Entes federados estejam em conformidade uns com os outros.

A gravidade do fato não reside apenas em não se estar cumprindo com o compromisso assumido pelo próprio Estado brasileiro, mas em se estar infringindo direitos constitucionalmente garantidos, a exemplo da garantia a um ambiente ecologicamente equilibrado, corolário do princípio do mínimo existencial ecológico. Isso significa que, ao se retardar a solução da questão dos lixões a céu aberto, que causam prejuízos irreparáveis ao meio ambiente, faz nascer ou posterga a violação aos direitos dos indivíduos ao mínimo existencial ecológico.

O estudo pretende responder às seguintes questões-problema: A ausência de um Plano Nacional de Resíduos Sólidos tem influência no atingimento das metas de eliminação e recuperação dos lixões no Brasil? Essa carência possui implicações no direito ao mínimo existencial ecológico? A hipótese que se pretende comprovar é que a inexistência de um Plano Nacional de Resíduos Sólidos possui influencia na concretização das metas de eliminação dos lixões no Brasil e, consequentemente, infringem o direito ao mínimo existencial ecológico.

Há quase 10 anos fora publicada a Lei. 12.305 de 2010 (BRASIL, 2010), que instituiu a Política Nacional de Resíduos Sólidos, que visava, dentre outras coisas, a eliminação e recuperação dos lixões no Brasil. A referida norma, por sua vez, foi fruto de 20 anos de debates sobre o tema, até que se concretizasse em norma legal. Transcorridos quase 30 anos desde o início dos debates, os lixões ainda são uma realidade muito presente no país, pouco avançando a questão da substituição dos lixões por aterros sanitários, ou de recuperação das áreas que ocupam.

Ao se analisar o teor da norma que instituiu a PNRS, constata-se que a União, que se comprometera a instituir (no prazo de quatro anos após a publicação da lei) Plano Nacional de Resíduos Sólidos, até o presente momento não publicou norma regulamentadora, de forma que Estados e Municípios permanecem sem um parâmetro a ser seguido para implementação das diretrizes contidas na lei. O retardo na implementação das medidas propostas na lei acaba por 
violar o princípio do mínimo existencial ecológico, que diz respeito ao direito a um meio ambiente ecologicamente equilibrado.

Neste sentido, o objetivo deste artigo é demonstrar que a ausência de um Plano Nacional de Resíduos Sólidos possui implicações no atingimento das metas de eliminação e recuperação dos lixões, bem como violam o princípio ao mínimo existencial ecológico. Inicialmente, pretende-se revisar a bibliografia e posicionamento jurisprudencial acerca do princípio do mínimo existencial ecológico; num segundo momento, revisar a bibliografia acerca da Política Nacional de Resíduos Sólidos, com enfoque nas metas de eliminação e recuperação dos lixões; e por fim, apresentar dados acerca da situação atual dos lixões no Brasil, de maneia superficial, em relação do princípio do mínimo existencial.

Com relação aos procedimentos metodológicos, optou-se pela abordagem indutiva por se tratar de um estudo específico e pesquisa qualitativa, considerando que se procederá para o levantamento bibliográfico e pesquisa teórica. Neste sentido, as técnicas empregadas para coleta e análise de dados foi a revisão bibliográfica, em leis, com levantamento de doutrinas especializadas, bem como pesquisa em artigos científicos sobre cada tema do objeto de pesquisa. Por fim, vale salientar que, houve a pesquisa de coleta de jurisprudências que mostram o perfil das violações de Direito sobre a Políticas de Resíduos sólidos no Brasil.

\section{O PRINCÍPIO DO MÍNIMO EXISTENCIAL ECOLÓGICO}

Dentre os bens elementares que a Ordem Jurídica buscou resguardar, o mais importante é o direito à vida, elencado no caput do artigo $5^{\circ}$ da Magna Carta como um direito fundamental individual. O Lei Maior não buscou resguardar a mera subsistência do indivíduo, mas garantir-lhe uma existência digna. A palavra dignidade, nesse contexto, corresponde a um atributo da pessoa humana, inerente a ela pelo simples fato de "ser humano", o que a torna merecedora de respeito e proteção (BRASIL, 1988).

Trata-se da materialização do princípio da dignidade da pessoa humana, elencado como um dos fundamentos da República Federativo do Brasil, que corresponde à base de todo o sistema constitucional brasileiro, influenciando na interpretação de quaisquer normas de caráter público ou privado, além de atuar como uma ponte de unificação entre todos os direitos fundamentais. Desta forma, o ser humano só gozará de vida digna quando tiver respeitados seus direitos mais elementares.

Conforme esclarece Motta (2013), a dignidade da pessoa humana possui uma dupla identificação, uma externa e outra interna. A identificação externa seria como um direito humano, cujo valor deve orientar aos demais princípios, direitos e deveres. Já a interna diz respeito a um eixo de tolerabilidade, que definiria até que ponto um determinado fato seria considerado tolerável pela coletividade.

No mesmo sentido, Sarlet (2001, p. 62) esclarece que dignidade humana é qualidade reconhecida do ser humano que o faz merecedor do mesmo respeito e consideração pelo Estado 
e pela comunidade, que se consubstancia em uma série de direitos e deveres fundamentais, os quais asseguram proteção contra todo e qualquer ato de cunho degradante e desumano, bem como garantem condições existenciais mínimas para uma vida saudável, além de propiciar e promover sua participação corresponsável nos destinos da própria existência e da vida em comunhão com os demais seres humanos.

\subsection{CONCEITO E EXTENSÃO DO MÍNIMO EXISTENCIAL ECOLÓGICO}

O conceito de dignidade da pessoa humana caminha junto ao do princípio do mínimo existencial, que diz respeito a certos bens, direitos ou oportunidades que devem ser garantidos em patamar mínimo aos indivíduos, sob pena de violação à dignidade da pessoa humana. $\mathrm{O}$ princípio do mínimo existencial ecológico, por sua vez, representa um prolongamento do mínimo existencial, especificamente, da garantia a um patamar mínimo e tolerável de equilíbrio ambiental, como forma de garantia de uma vida digna à população, a qual se manifestaria através do acesso à água potável, serviços de coleta e destinação adequada de resíduos sólidos, dentre outros fatores.

Ante o exposto, torna-se fundamental a compreensão do viés ecológico da dignidade humana, uma vez que a qualidade ambiental mínima é necessária a existência digna, e o meio ambiente equilibrado constitui um dos elementos dessa dignidade. Constata-se que a dignidade da pessoa humana perpassa pelo conceito de desenvolvimento sustentável, englobando não apenas a questão econômica e social, mas também a manutenção do equilíbrio ecológico, constitucionalmente assegurado.

É o que se extrai do caput do artigo 225 da Carta magna, in verbis: "Todos têm direito ao meio ambiente ecologicamente equilibrado, bem de uso comum do povo e essencial à sadia qualidade de vida, impondo-se ao Poder Público e à coletividade o dever de defende-lo e preserválo para as presentes e futuras gerações" (BRASIL, 1988).

Conforme as esclarecedoras lições de Steigleder (2002, p, 280), a garantia ao mínimo existencial ecológico corresponde a garantir condições mínimas de subsistência para a vida e saúde da população, sem riscos para sua vida e saúde, ou danos irreparáveis ao meio ambiente. A autora ressalta, ainda, que lograr uma existência digna partiria de um direito à obtenção de prestações públicas em condições de mínimas na seara ambiental. Como exemplo de violação ao mínimo existencial ecológico, causadora de graves riscos à saúde e vida da população, bem como de danos irreparáveis ao ambiente, a autora cita a deposição de lixo urbano a céu aberto, que além de gerar perigos à saúde da população circundante, pode causar a contaminação dos corpos hídricos, bem como do ar com poluentes prejudiciais à saúde humana.

Esse mínimo existencial deve ser visualizado em duas dimensões distintas: uma negativa, que corresponde ao direito de não ser privado do que se considera essencial à conservação de uma existência minimamente digna; e uma positiva, que diz respeito ao direito de exigir do Estado prestações que traduzam esse mínimo.

Há que se destacar, ainda, a aproximação da dignidade da pessoa humana com os direitos 
sociais, elencados no artigo $6^{\circ}$ da Constituição Federal. Isso implica que, a vida digna só será alcançada se garantidos em patamares desejáveis constitucionalmente os direitos à educação, à saúde, à alimentação, ao trabalho, à moradia, ao transporte, ao lazer, à segurança, à previdência social, à proteção à maternidade e à infância, bem como assistência aos desamparados. Cada qual com um nível mínimo tolerável que deve ser mantido.

Nesse sentido Fensterseifer (2008, p. 74), destaca que para a conformação do conteúdo do princípio da dignidade da pessoa humana, seria necessário o diálogo deste com o direito fundamental ao ambiente e com os direitos sociais, já que representam os elementos mais importantes para a existência digna e saudável.

\subsection{FUNDAMENTALIDADE DO MÍNIMO EXISTENCIAL ECOLÓGICO}

Inicialmente, cumpre destacar que a expressão direito fundamental não é sinônimo de direito humano. Os direitos fundamentais correspondem aos direitos objetivamente reconhecidos e positivados por uma ordem jurídica oficial. São, por isso, delimitados espacial e temporalmente, isto é, variam segundo a ideologia, a modalidade de Estado, as espécies de valores e princípios que a Constituição consagra. Cada Estado consagra o seu próprio rol de direitos fundamentais.

Por seu turno, os direitos humanos são aqueles reconhecidos aos indivíduos e grupos de pessoas independentemente de qualquer vinculação com determinada ordem constitucional. São posições jurídicas reconhecidas ao ser humano enquanto tal, independentemente de seu vínculo jurídico com determinado Estado.

Pela leitura do art. 225 da CRFB, constata-se o enquadramento do direito ao meio ambiente como um direito fundamental, possuindo supremacia normativa, caráter vinculante e aplicabilidade imediata, em virtude do comando inserto no $\S 1^{\circ}$ do art. $5^{\circ}$ da Constituição Federal de 1988, e condição de cláusula pétrea, com força no art. $60, \S 4^{\circ}$ da Lei Maior.

Está consagrado na Jurisprudência do Superior Tribunal de Justiça que o ambiente ecologicamente equilibrado constitui modalidade direito fundamental, mesmo que ausente no rol elencado art. $5^{\circ}$ da CRFB, nesse sentido, cabível citar teor de acórdão da corte superior, in verbis:

ADMINISTRATIVO. RECURSO ESPECIAL. DANO AMBIENTAL. CONDENAÇÃO. ART. $3^{\circ}$ DA LEI 7.347/85. CUMULATIVIDADE. POSSIBILIDADE. OBRIGAÇÃO DE FAZER OU NÃO FAZER COM INDENIZAÇÃO. RECURSO PARCIALMENTE PROVIDO. [...] 2. O meio ambiente equilibrado - elemento essencial à dignidade da pessoa humana -, como "bem de uso comum do povo e essencial à sadia qualidade de vida" (art. 225 da CF), integra o rol dos direitos fundamentais. 3. Tem o meio ambiente tutela jurídica respaldada por princípios específicos que lhe asseguram especial proteção. 4. O direito ambiental atua de forma a considerar, em primeiro plano, a prevenção, seguida da recuperação e, por fim, o ressarcimento. [....]" (REsp 1115555/MG, Rel. Ministro Arnaldo Esteves Lima, Primeira Turma, julgado em 15/02/2011, DJe 23/02/2011). 
Miralé (2011, p. 136) classificou o mínimo existencial ecológico como direito fundamental personalíssimo, essencial à plena realização humana. O que é feito de forma acertada, já que, tratase de direito expressamente previsto no texto constitucional e por sua natureza, possui eficácia plena e aplicabilidade imediata.

Nesse interim, durante o julgamento do RESP 575.998-MG, a $1^{\circ}$ Turma do STJ manifestou entendimento sobre a possibilidade de controle judicial em razão de prestação descontinuada de coleta de lixo por parte da Administração Pública, sob o argumento de que a omissão administrativa acarretou prejuízo ao direito fundamental à saúde, ao ambiente e à dignidade da pessoa humana, bem como que não há discricionariedade do administrador frente aos direitos consagrados constitucionalmente.

Denota-se que o Estado não possui apenas a faculdade, mas o dever de implementar políticas públicas que tenham como meta garantir o direito fundamental ao meio ambiente ecologicamente equilibrado e ao mínimo existencial ecológico, sob pena de ser acionado judicialmente e de ser compelido a cumprir aquilo que assumiu como compromisso. Nesses casos, sequer seriam aceitas teses de defesa pautadas na "reserva do possível" ou "separação de poderes", uma vez que estão imersas em políticas públicas que visam assegurar compromissos assumidos pelo Estado brasileiro, devido a sua fundamentalidade.

É o que ficou firmado durante o julgamento do AgRg no REsp 1211989, de relatoria do Ministro Benedito Gonçalves, em que se consagrou que não há violação à separação de poderes na intervenção do Judiciário para a garantia de políticas públicas de acesso a água, com fundamento no direito ao mínimo existencial ecológico.

Como se observa, embora a Constituição Federal de 1988 apresente um extenso rol de direitos fundamentais em seu art. $5^{\circ}$, este não é taxativo, já que o Estado brasileiro adota o conceito de fundamentalidade aberta. Isso significa que os direitos e garantias contidos na Lei Maior não excluem outros decorrentes de princípios por ela adotados ou de Tratados Internacionais que o Brasil seja signatário.

Destaque-se, ainda, que devido à publicação da Emenda Constitucional n. 45/2004, a incorporação de tratados e convenções internacionais sobre direitos humanos, do qual o meio ambiente é espécie, como equivalentes às Emendas Constitucionais.

Via de consequência, não pairam dúvidas de que o mínimo existencial ecológico, corolário da garantia ao meio ambiente ecologicamente equilibrado, é caracterizado como direito fundamental, tendo aplicabilidade imediata e vinculam os poderes constituídos na formulação e implementação de políticas públicas. Caracterizado o direito, faz-se necessário conferir eficácia a este direito fundamental, eficácia jurídica e efetividade social.

Nesse sentido, como esclarece Barroso (2011, p. 83), efetividade significa a realização do Direito, o desempenho concreto de sua função social, representando, ainda, a materialização, no mundo dos fatos, dos preceitos legais, simbolizando a íntima aproximação entre o dever ser normativo e o ser da realidade social. A eficácia social representa ao reflexo real que a norma produz na sociedade, sendo obedecida e aplicada. Por seu turno, a eficácia jurídica designa a qualidade 
de produzir, em menor ou maior grau, efeitos jurídicos, trazendo desde logo a possibilidade de ser executada e exigível.

Cumpre salientar que, por conta do Princípio da Efetividade da Constituição, o intérprete deve conferir a máxima efetividade possível à norma constitucional, já que o direito existe para ser realizado. Ao Estado cabe, ainda, impedir que os particulares criem embaraços à fruição do direito fundamental ao meio ambiente ecologicamente equilibrado por parte dos demais indivíduos e da sociedade em geral.

\section{A POLÍTICA NACIONAL DE RESÍDUOS SÓLIDOS}

O ser humano utiliza recursos naturais para satisfazer suas necessidades, sejam elas de alimentação, de vestuário, de habitação, dentre outras. Os recursos utilizados na fabricação de produtos ou na prestação desses serviços. Aquilo que sobra do processo produtivo é o que se denomina lixo, resíduo ou rejeito, que se não gerido da forma correta, tornam-se responsáveis pela degradação ambiental.

O lixo diz respeito a tudo o que se joga fora, por ser considerado inútil, velho, sem valor. Corresponde aos restos das atividades humanas consideradas pelos seus geradores como inúteis, indesejáveis ou descartáveis, podendo se apresentar na forma sólida ou líquida, desde que não seja passível de tratamento.

Resíduo diz respeito àquilo que pode ser reutilizado e reciclado, podendo ser utilizado como matéria-prima para um novo produto ou processo. Pode ser encontrado na forma sólida (resíduos sólidos), líquida (efluentes) ou gasosa (gases e vapores).

O rejeito, por sua vez, diz respeito aos "resíduos sólidos que, depois de esgotadas todas as possibilidades de tratamento e recuperação por processos tecnológicos disponíveis e economicamente viáveis, não apresentem outra possibilidade que não a disposição final ambientalmente adequada" (art. $\left.3^{\circ}, \mathrm{XV}\right)$.

O conceito fundamental para o presente estudo é o de resíduo sólido, que corresponde ao "material, substância, objeto ou bem descartado resultante de atividades humanas em sociedade, a cuja destinação final se procede, se propõe proceder ou se está obrigado a proceder, nos estados sólido ou semissólido, bem como gases contidos em recipientes e líquidos cujas particularidades tornem inviável o seu lançamento na rede pública de esgotos ou em corpos d'água (...)" (Art. $3^{\circ}$, XVI).

Há que se destacar que, durante anos houve a exploração desordenada dos recursos naturais, bem como o descarte inadequado das sobras do processo, os quais foram responsáveis por grandes problemas ambientais, com destaque para a aceleração do processo de aquecimento global pelo aumento de emissão de gases poluentes, sobretudo pela queima de combustíveis fósseis.

No Brasil, esse pensamento ambiental culminou na sanção da Lei 6.938/1981 (BRASIL, 1981), que instituiu a Política Nacional do Meio Ambiente, que disciplinou de forma sistematizada o meio ambiente. Dentre os objetivos da norma, destaca-se aquele instituído em seu artigo $4^{\circ}$, 
inciso I, que estabelece a necessidade de "compatibilização do desenvolvimento econômico-social com a preservação da qualidade do meio ambiente e do equilíbrio ecológico".

Foi instituída a obrigatoriedade de o Poder Público promover a edição de políticas públicas visando a preservação da qualidade ambiental e do equilíbrio ecológico. O que foi recepcionado pela Constituição Federal de 1988, que em seu artigo 225, parágrafo $1^{\circ}$ estabeleceu o dever do Poder Público de assegurar a efetividade do direito ao meio ambiente ecologicamente equilibrado (BRASIL, 1988).

Uma destas medidas foi a Política Nacional de Resíduos Sólidos PNRS, instituída pela lei $\mathrm{n}^{\mathrm{o}}$ 12.305, de 2 de agosto de 2010 (BRASIL, 2010), com o objetivo de reduzir o impacto dos resíduos sólidos no meio ambiente, através da implementação de uma gestão compartilhada e integrada de resíduos, impondo regras para todos os setores da indústria, disciplinando todo o ciclo de vida do produto, o qual, segundo o inciso IV, do art. $3^{\circ}$ da PNRS, representa uma "série de etapas que envolvem o desenvolvimento do produto, a obtenção de matérias-primas e insumos, o processo produtivo, o consumo e a disposição final" (BRASIL, 2010).

Quanto às diretrizes da norma, é de fundamental importância citar o teor do artigo $9^{\circ}$ da Lei 12.305, o qual esclarece que: "Na gestão e gerenciamento de resíduos sólidos, deve ser observada a seguinte ordem de prioridade: não geração, redução, reutilização, reciclagem, tratamento dos resíduos sólidos e disposição final ambientalmente adequada de rejeitos” (BRASIL, 2010).

Torna-se evidente a influência do conceito de desenvolvimento sustentável, elencado como um dos princípios da PNRS, o qual busca não apenas viabilizar o desenvolvimento econômico do país, mas também compatibilizá-lo com a preservação da qualidade ambiental e equilíbrio ecológico. Para tanto, estabelece como seu fim primordial a não geração de resíduos sólidos, mas nos casos de impossibilidade, estabelece outras medidas que devem ser adotadas para minorar o impacto ambiental. Isso significa que todo resíduo deve ser processado adequadamente antes de ser descartado e, sempre que possível, buscar sua reutilização, através dos instrumentos elencados pela PNRS, especificamente, a reciclagem, a logística reversa, coleta seletiva e compostagem.

A norma tratou de compartilhar a responsabilidade pelo gerenciamento de resíduos entre o poder público e o privado, durante cada um dos ciclos de vida dos produtos. Isso implica que, fabricante, comerciante, importador, distribuidor comercial e consumidores possuem determinado grau de responsabilidade pela destinação dos resíduos.

Ao governo, cabe estabelecer planos, garantir a infraestrutura, organizar e fiscalizar o cumprimento da lei. Ao setor privado a responsabilidade de recuperá-los e fazer o descarte correto. E à população, o papel de separar e preparar seus resíduos, limpando-os para que estejam prontos para a reciclagem. Destaque-se que incumbe essencialmente ao aos municípios e ao Distrito Federal a gestão integrada de resíduos sólidos, mas sem extinguir a responsabilidade dos Estados e da União para o atingimento das metas elencados na PNRS.

Os instrumentos que possibilitam o enquadramento à legislação são elencados no artigo $8^{\circ}$ da PNRS, dos quais se destacam: 
o plano de resíduos sólidos, que deve descrever a atividade exercida pelo ente, o diagnóstico dos resíduos sólidos gerados, bem como as ações que visem prevenir ou restabelecer as condições ambientais;

inventário e declaração dos resíduos produzidos no ano anterior;

sistema de coleta seletiva, logística reversa, em que se estabeleça estratégias de implementação de responsabilidade compartilhada durante o ciclo de vida do produto;

colaboração financeira e técnica entre o setor público e o privado para o desenvolvimento de pesquisas, métodos e ferramentas e tecnologia de gestão de resíduos, envolvendo reciclagem, reutilização de disposição final ambientalmente apropriadas.

O presente estudo buscará dar um enfoque aos Planos de Resíduo Sólidos, com destaque ao Plano Nacional de Resíduos Sólidos e sua influência no atingimento das metas de eliminação e recuperação dos lixões.

\subsection{PLANOS DE NACIONAL DE RESÍDUOS SÓLIDOS}

Os planos de resíduos sólidos representam projetos sistemáticos de gestão de resíduos sólidos, que visam dar efetividade às normas da Política Nacional de Resíduos Sólidos.

As modalidades de resíduos sólidos são elencadas no artigo 14 da PNRS, sendo os principais o Plano Nacional de Resíduos Sólidos, os Planos Estaduais de Resíduos Sólidos e os Planos Municipais de Resíduos Sólidos.

A Política Nacional de Resíduos Sólidos, em seu art. 15, determinou que a União deveria elaborar, sob coordenação do Ministério do Meio Ambiente, o Plano Nacional de Resíduos Sólidos, com vigência por prazo indeterminado e horizonte de 20 (vinte) anos, a ser atualizado a cada 4 (quatro) anos. O prazo para elaboração do plano encerrou em agosto de 2012, mas ainda se encontra em versão preliminar desde 2011 (BRASIL, 2010)

O plano deveria conter, necessariamente, os seguintes elementos:

I - diagnóstico da situação atual dos resíduos sólidos;

II - proposição de cenários, incluindo tendências internacionais e macroeconômicas;

III - metas de redução, reutilização, reciclagem, entre outras, com vistas a reduzir a quantidade de resíduos e rejeitos encaminhados para disposição final ambientalmente adequada;

IV - metas para o aproveitamento energético dos gases gerados nas unidades de disposição final de resíduos sólidos;

V - metas para a eliminação e recuperação de lixões, associadas à inclusão social e à emancipação econômica de catadores de materiais reutilizáveis e recicláveis;

VI - programas, projetos e ações para o atendimento das metas previstas;

VII - normas e condicionantes técnicas para o acesso a recursos da União, para a obtenção de seu aval ou para o acesso a recursos administrados, direta ou indiretamente, por entidade federal, quando destinados a ações e programas de 
interesse dos resíduos sólidos;

VIII - medidas para incentivar e viabilizar a gestão regionalizada dos resíduos sólidos;

IX-diretrizes para o planejamento e demais atividades de gestão de resíduos sólidos das regiões integradas de desenvolvimento instituídas por lei complementar, bem como para as áreas de especial interesse turístico;

$\mathrm{X}$ - normas e diretrizes para a disposição final de rejeitos e, quando couber, de resíduos;

XI - meios a serem utilizados para o controle e a fiscalização, no âmbito nacional, de sua implementação e operacionalização, assegurado o controle social (BRASIL, 2010).

Houve cinco audiências públicas regionais e uma nacional, que culminaram na elaboração de uma proposta de Plano Nacional de Resíduos sólidos, a qual foi encaminhada, pelo então Ministro do Meio Ambiente, ao presidente para ser validado através de Decreto, mas o plano preliminar nunca chegou a ser implementado.

Por simetria, os elementos do Plano Nacional deveriam estar presentes nos Planos Estaduais de Resíduo Sólido, adaptando-os para questões regionais. O conteúdo mínimo dos planos estaduais está descrito no artigo 17 da PNRS, dos quais ressalta-se aquele contido no inciso ' $\mathrm{X}$ ', que estabelece que as normas e diretrizes para a disposição final de rejeitos e, quando couber, de resíduos, deverão balizar-se pelas disposições estabelecidas pelo Plano Nacional de Resíduos Sólidos.

Os Planos Estaduais de Resíduos Sólidos deverão apontar caminhos e orientar investimentos, além de subsidiar e definir diretrizes para os planos das regiões metropolitanas, aglomerações urbanas e microrregionais, bem como para os planos municipais de gestão integrada e para os planos de gerenciamento dos grandes geradores de resíduos.

Por seu turno, os Planos Municipais de Resíduos Sólidos é que, a grosso modo, orientaram a gestão organizada e integrada dos resíduos sólidos. O conteúdo mínimo que deverão comportar estão elencados no artigo 19 da PNRS, dos quais destaca-se os seguintes: a identificação de áreas favoráveis à disposição ambientalmente adequada para os rejeitos; a elaboração de programas de educação ambiental para a promoção da não geração, a redução, a reutilização e reciclagem de resíduos sólidos; elaboração de programas e ações para participação de grupos interessados, como cooperativas ou associações de catadores de materiais reutilizáveis e recicláveis; criação de mecanismos para criação de fontes de negócio, emprego e renda, mediante valorização de resíduos sólidos; descrição das formas e limites de participação do poder público local a coleta seletiva e na logística reversa.

A elaboração dos planos estaduais e municipais são condição para obtenção de recursos da União, ou por ela controlados, para empreendimentos e serviços relacionados à gestão de resíduos sólidos. É de fundamental importância, ainda, a compreensão do conceito de Plano de Gerenciamento de Resíduos Sólidos, que corresponde ao documento técnico que identifica a tipologia e quantidade de geração de cada tipo de resíduos e indica formas ambientalmente corretas 
para o manejo, nas etapas de geração, acondicionamento, transporte, transbordo, tratamento, reciclagem, destinação e disposição final.

Destinam-se aos geradores de resíduos sólidos responsáveis pelo adequado gerenciamento de seus resíduos, no caso: geradores de resíduos de serviços públicos de saneamento básico; geradores de resíduos industriais; geradores de resíduos de serviços de saúde; geradores de resíduos de mineração; estabelecimentos comerciais e de prestação de serviços que gerem resíduos perigosos ou que sejam definidos como de responsabilidade privada por sua natureza, composição ou volume; empresas de construção civil; terminais ou outras instalações de sérvios de transporte e atividades agrossilvopastoris conforme exigências do órgão ambiental ou vigilância sanitária.

\subsubsection{Das metas de eliminação e recuperação de lixões}

De acordo com o artigo 54 da Lei 12.305/2010, a disposição final ambientalmente adequada dos rejeitos deveria ser implementada em até 04 (quatro) anos após a publicação da referida norma. Isso significa que o prazo para o encerramento de todos os lixões e estabelecimento de métodos adequados de deposição dos resíduos sólidos no país se encerraria em 2014, contudo, diante da desídia estatal, houveram poucos avanços nesse sentido.

Em julho de 2015, o Senado estendeu a data-limite para o fim dos lixões, com isso, capitais e regiões metropolitanas, além de municípios de fronteira e as que contavam com mais de 100 mil habitantes, com base no Censo de 2010, ganharam prazo até o final de 2019, para encerrarem seus lixões e darem a destinação correta a seus rejeitos. Mais uma vez violado o prazo estabelecido para cumprimento da meta.

Para cidades com população entre 50 e 100 mil habitantes o prazo se encerra em 31 de julho de 2020 e, para os municípios com população inferior a 50 mil habitantes, se encerra em 31 de julho de 2021.

Nestes dois últimos casos, é dado como certo que os prazos não serão cumpridos, uma vez que, de acordo com os dados que serão listados adiante, o país pouco avançou na resolução do problema, de forma que ainda estão em funcionamento grande número de lixões no país e números indicam um crescimento no quantitativo de rejeitos que são destinados a lixões.

Segundo o estudo "Solucionar a Poluição Plástica: Transparência e Responsabilização", elaborado pelo Fundo Mundial Para a Natureza (WWF), o Brasil é o quarto país do mundo que mais produz lixo. Os municípios brasileiros são responsáveis pela produção de 11.355.220 toneladas de lixo plástico por ano, destes, apenas $1,28 \%$ é reciclado.

Tudo caminha para uma nova prorrogação dos prazos para eliminação e recuperação dos lixões, evidenciando, cada vez mais, o caráter simbólico da PNRS, representando um mero documento impresso, desprovido de efetividade. 


\section{RELAÇÃO ENTRE O PRINCÍPIO DO MÍNIMO EXISTENCIAL ECOLÓGICO E O POLÍTICA NACIONAL DE RESÍDUOS SÓLIDOS NA SITUAÇÃO ATUAL DOS LIXÕES NO BRASIL}

Conforme destacado alhures, o princípio do mínimo existencial ecológico representa verdadeiro direito fundamental, razão pela qual o Estado brasileiro tem o dever de promover políticas públicas que assegurem a garantia a um patamar mínimo e tolerável de equilíbrio ambiental, como forma de garantia de uma vida digna à população.

A não implementação dessas políticas ou sua implementação defeituosa (realizada sem a garantia da máxima efetividade do preceito fundamental), enseja a configuração de grave violação ao mínimo existencial ecológico.

A PNRS foi construída a partir do planejamento em todos os níveis abrangendo do nacional ao local, de modo que a União estados e municípios são obrigados a formularem seus planos. Isso significa que o poder público deve apresentar planos para o manejo correto dos materiais, as empresas devem se responsabilizar pelo recolhimento dos produtos após o uso e a sociedade participaria do ciclo através dos programas de coleta seletiva ou acondicionando os resíduos adequadamente antes da coleta, além de incorporarem mudanças de habito para reduzir o consumo e a consequente geração.

Destaque-se que a participação da sociedade é fundamental para a construção dos planos de gestão de resíduos sólidos. O início da mudança nos hábitos e de comportamento da sociedade passa pelo processo conscientização para a sensibilização (VGRESÍDUOS, 2017).

Quando analisamos o cenário atual dos lixões no Brasil, constatamos que o mínimo existencial ecológico persiste em ser violado, já que as medidas necessárias para promover a eliminação e recuperação dos lixões não são adotadas ou não são utilizadas da forma correta, de modo que, apenas uma pequena parcela dos resíduos produzidos tem a destinação final adequada.

As destinações mais comumente utilizadas para os resíduos sólidos são:

Lixão ou depósito a céu aberto - que diz respeito à deposição dos resíduos sólidos no ambiente, sem estudos ambientais ou monitoramento;

Aterro controlado - distingue-se do depósito a céu aberto pelo fato de o lixo ser coberto com terra no momento da deposição, sem que haja um sistema de coleta ou drenagem do chorume, líquido poluente que atinge os lençóis freáticos, nem a captação e o controle da queima dos gases gerados;

Aterro sanitário - corresponde a um dos métodos adequados de deposição final de resíduos sólidos. Neste caso é necessário haver uma manta protetora do solo para impedir a contaminação por chorume e os resíduos são dispostos em menor escala, os quais são cobertos, ao menos diariamente, por uma camada de terra. Através deste método pode haver o aproveitamento do gás metano liberado no processo de decomposição para a geração de energia;

Usina de compostagem - transforma a matéria orgânica do lixo e demais resíduos sólidos em nutrientes que podem ser utilizados nas áreas agrícolas;

Reciclagem - consiste no reaproveitamento dos resíduos sólidos na produção de novos produtos; 
Incineração - corresponde a forma adequada de tratamento final de resíduos sólidos de origem industrial e dos intitulados inertes.

O Brasil é o quarto país do mundo que mais produz lixo e um dos que menos recicla, apenas $1,28 \%$ do lixo plástico produzido pelos municípios brasileiros é reciclado, sendo de $9 \%$ a média mundial (WWF, 2019).

Segundo dados da Associação Brasileira de Empresas de Limpeza Pública e Resíduos Especiais (ABRELPE), 41\% de todo o lixo produzido anualmente no Brasil vai para onde não devia: rios, mares e lixões. O que é terminantemente proibido pela PNRS, que em seu artigo 47, veda o lançamento de resíduos sólidos em praias, no mar ou quaisquer corpos hídricos; o lançamento in natura a céu aberto, excetuados os resíduos de mineração; bem como a queima a céu aberto ou em recipientes, instalações e equipamentos não licenciados para essa finalidade (ABRALPE, 2019).

Ainda segundo a Abrelpe, no ano de 2019, o país ainda apresentava quase 3 mil lixões e aterros inadequados (aterros controlados), dispostos por mais de 2500 cidades com lixões, onde são despejados mais de 12,9 milhões de toneladas de lixo por ano (ABRALPE, 2019).

Os aterros sanitários, considerados como a técnica adequada para a deposição de resíduos sólidos, estão presentes em 2.182 municípios. Segundo o Panorama dos Resíduos Sólidos 2018/2019, em 2018, a geração de resíduos sólidos urbanos no Brasil foi de 79 milhões de toneladas, dos quais $92 \%$ foram coletados. Nesse período, a produção de lixo aumentou $1 \%$ e a coleta aumento 1,66\%. Dos resíduos coletados em 2018, 59,5\% foram adequadamente destinadas aos aterros sanitários, um aumento de 2,4\% em relação a 2017. Mas, ainda 2019 8\% do lixo produzido (6,3 toneladas) sequer são coletados e $40 \%$ do que é coletado é destinado a lixões ou aterros controlados (RECICLASAMPA, 2019).

Segundo dados do IBGE de 2017, quase metade das 5.570 cidades brasileiras, não possuíam um plano integrado de manejo do lixo. A grande problemática enfrentada para a elaboração desses planos integrados está contida no enquadramento aos 19 itens (requisitos) obrigatórios estabelecidos na PNRS. No âmbito nacional, apenas 2.126 municípios $(38,2 \%)$ afirmavam possuir plano de saneamento básico em 2017 (IBGE, 2018).

O estudo apontou que a existência do plano é mais comum nos municípios mais populosos. Entre os 42 municípios com população superior a 500 mil habitantes, 69\% declararam possuir plano de gestão do lixo. Enquanto isso, nas cidades com população variante de 5.001 e 10.000 habitantes, apenas $61,7 \%$ apresentavam o plano (IBGE, 2018).

Os impactos do despejo inadequado de resíduos sólidos no ambiente são tremendos, contaminando a água, o solo e o ar e afetando diretamente a saúde da população que reside no entorno desses lixões, bem como aquelas que são beneficiadas (ou prejudicadas) pela água proveniente dos lençóis freáticos e dos rios e córregos atingidos pelo chorume produzido na decomposição dos materiais.

Quando questionamos as dificuldades para o atingimento das metas de eliminação e 
recuperação de lixões, a primeira resposta que surge é a falta de recursos dos municípios, sobretudo, porque, como mencionado anteriormente, muitos não possuem plano de gestão integrada, consequentemente não tem acesso aos recursos da União ou por ela controlados. Segundo dados da Abrelpe, em 2017, 65\% dos municípios não teriam receita específica para cuidar do lixo, mesmo sendo uma atribuição das prefeituras. Em 2018, 59\% dos municípios ainda afirmavam não dispor de planos próprios sobre o destino de resíduos sólidos (ABRALPE, 2019).

Conforme dados do Sistema Nacional de Informações Sobre Saneamento - SNIS, ligado ao Ministério do Desenvolvimento Regional, em 2018, apenas 47\% dos municípios brasileiros apresentavam algum tipo de cobrança para custeio do manejo de resíduos sólidos urbanos, ainda assim, apenas 54,3\% dos custos eram alcançados pela cobrança (SNIS, 2018).

Outro ponto que merece destaque diz respeito aos custos elevados para a construção de aterros sanitários. Lins (2019) afirma que "o aterro sanitário é uma estrutura cara, de operação e manutenção complexas e que só é viável economicamente para municípios de mais de 100 mil habitantes". Ressalta, ainda, que cerca de $90 \%$ dos municípios brasileiros possuem menos de 50 mil habitantes.

Uma questão pouco lembrada, e que motivou a elaboração do presente estudo, é a influência da não sacramentação do Plano Nacional de Resíduos Sólidos no atingimento das metas de eliminação e recuperação dos lixões. Como destacado, desde 2011 que projeto preliminar do Plano Nacional de Resíduos Sólidos está elaborado, tendo seguido todos os procedimentos exigidos pela PNRS, mas por puro desinteresse do Chefe do Executivo, nunca chegou a ser convertido em Decreto.

Levando-se em consideração o inciso ' $X$ ' dos artigos 15 e 17 da PNRS, os Planos Estaduais de Resíduos Sólidos devem embasar-se no Plano Nacional de Resíduos Sólidos, e os planos Municipais serão balizados nos Planos Estaduais. Trata-se de uma verdadeira concatenação de planos, mas que se veem impossibilitados de atingir seus fins, ante a desídia da União. Como um corpo que não pode existir sem a cabeça, não há como se exigir que Estados e Municípios pratiquem atos coordenados para a promoção da eliminação e recuperação dos lixões, se a União não dá sua parcela de contribuição.

Por mais que se tente argumentar que a participação da União estaria garantida pela criação de programas de fiscalização e controle como o SISNAMA (Sistema Nacional do Meio Ambiente), SINIR (Sistema Nacional de Informações Sobre Gestão dos Resíduos Sólidos), e SNIS (Sistema Nacional de Informação Sobre Saneamento), bem como pela destinação de recursos aos municípios e estados, este posicionamento não merece prosperar

Nesse momento faz-se necessário um regresso às funções administrativas básicas, para recordarmos que cabe à administração, primeiramente, planejar, ou seja, estabelecer os objetivos que se pretende alcançar, bem como os caminhos que deverão ser trilhados para que o fim seja alcançado. A seguir, compete-lhe organizar, colocar em prática aquilo que foi planejado, definindo a forma como o projeto será executado. A terceira função a ser exercida é a de direção, que corresponde a liderar, mobilizando os recursos disponíveis para que o resultado seja alcançado 
(COALISE, 2020).

Aparentemente, a União tem atentado apenas para a última das funções, que diz respeito ao controle, o método utilizado para acompanhar se o plano definido está sendo cumprido, bem como possibilita ações corretivas para o redirecionamento dos esforços para o caminho que foi traçado (COALISE, 2020). Porém, ficam os questionamentos: Como acompanhar e gerenciar o cumprimento de planos que não foram por ela elaborados? Como exigir coordenação dos planos sem um modelo que possa ser seguido pelos demais entes federados? Existe possibilidade de sucesso no atingimento das metas sem a definição de plano de âmbito nacional?

Mesmo se houvessem sido cumpridas as determinações da PNRS e definido o Plano Nacional de Resíduos Sólidos, este já deveria ter passado por alterações para se adaptar às novas realidades. Certo é que que não há sequer uma data prevista para a definição deste plano, o que é de extrema gravidade, pois a degradação ambiental persiste e, consequentemente, perduram as violações aos direitos constitucionalmente garantidos ao meio ambiente ecologicamente equilibrado e ao mínimo existencial ecológico.

\section{CONSIDERAÇÕES FINAIS}

No Brasil, está constitucionalmente garantido o direto à vida com dignidade, sendo um dos elementos desta dignidade o meio ambiente ecologicamente equilibrado. Como consectário da garantia ao equilíbrio ambiental, tão fundamental à sobrevivência do ser humano, está o mínimo existencial ecológico, o qual se manifestaria através do acesso à água potável, serviços de coleta e destinação adequada de resíduos sólidos, dentre outros fatores. No entanto, a carência no atingimento das metas de eliminação e recuperação dos lixões no Brasil possui implicações no direito ao mínimo existencial ecológico.

O Estado tem o dever de promover políticas públicas que visem assegurar o cumprimento do direito fundamental ao meio ambiente ecologicamente equilibrado e ao mínimo existencial ecológico, podendo ser acionado judicialmente e ser compelido a cumprir com o dever por ele assumido. Logo, a ausência de um Plano Nacional de Resíduos Sólidos tem influência no atingimento das metas de eliminação e recuperação dos lixões no Brasil.

Apesar da existência deste dever legal, ele é constantemente violado. O simples fato de não serem adotadas medidas que seriam necessárias para resolver ou minimizar os impactos ambientais já configuram violações ao princípio do mínimo existencial ecológico e ao direito ao ambiente ecologicamente equilibrado. São exemplos claros desta violação o não fornecimento (ou o fornecimento defeituoso) de serviços de água tratada, de coleta de seletiva e de disposição final adequada de resíduos sólidos.

Outro exemplo a ser citado, e aquele que motivou a elaboração do presente estudo, é a não implementação do Plano Nacional de Resíduos Sólidos, que deveria ser utilizado como parâmetro para os demais entes federativos na elaboração de suas políticas públicas de enfrentamento da questão dos resíduos sólidos. 
De acordo com a PNRS, os lixões no país deveriam ter sido eliminados e, os terrenos por eles ocupados, recuperados até o ano de 2014. Contudo, ainda existem mais de 3 mil lixões e aterros irregulares em funcionamento no país. A falta de recursos dos municípios, somada aos altos custos da implementação de aterros sanitários, bem como pela ausência de participação da União na elaboração de planos e projetos para o enfrentamento do problema, são os grandes fatores que fazem com que o atingimento das metas de eliminação dos lixões seja uma realidade tão distante.

A solução do problema se iniciaria pela definição da Política Nacional de Resíduos Sólidos, que analisando o cenário atual dos resíduos sólidos, bem como as tendências internacionais e macroeconômicas, traçariam estratégias para o enfrentamento a nível nacional, coordenando a atuação dos estados e municípios. Desta forma, seria permitida a destinação mais adequada e melhor direcionada dos recursos, municiando àquelas regiões que apresentem maiores dificuldades para a solução do problema.

Outro ponto de destaque seria envolver a população na resolução da questão, não apenas através de políticas educacionais que estimulem a redução do consumo e produção do lixo, ou pela separação dos resíduos que serão coletados, mas também pela implementação de um sistema de remuneração direta pelos usuários, como acontece em outros países e em outros setores da infraestrutura no Brasil, inserindo a população no enfrentamento do problema. O que não pode ocorrer é permanecer da forma como está, sem a atuação conjunta dos estados e municípios e prorrogando ad eternum o prazo para eliminação e recuperação de lixões.

\section{REFERÊNCIAS}

ABES, Associação Brasileira de Engenharia Sanitária e Ambiental. Brasil tem quase 3 mil lixões ou aterros irregulares. Disponível em: <http://www.abes-mg.org.br/visualizacao-de-clipping/ ler/8637/brasil-tem-quase-3-mil-lixoes-ou-aterros-irregulares> Acesso em: 15 abril 2020.

ABRELPE, Associação Brasileira de Empresas de Limpeza Pública. Os descaminhos do lixo. 27 nov. 2019. O Estadão - Opinião. Disponível em: <http://abrelpe.org.br/brasil-produz-mais-lixomas-nao-avanca-em-coleta-seletiva/> Acesso em: 10 abril 2020.

Acesso em: 10 abril 2020.

BARROSO, Luis Roberto. O Direito constitucional e a efetividade de suas normas. Rio de Janeiro: Renovar, 2011.

BRASIL, Constituição da República Federativa do. Congresso Nacional, Brasília, 1988. Disponível em: http://www.planalto.gov.br/ccivil_03/constituicao/constituicao.htm. Acesso em: 10 abril 2020.

BRASIL. Lei 12.305, de 02 de agosto de 2010. Institui a Política Nacional de Resíduos Sólidos; altera a Lei no 9.605, de 12 de fevereiro de 1998; e dá outras providências. Brasília, 2010. Disponível em: http://www2.mma.gov.br/port/conama/legiabre.cfm?codlegi=636. Acesso em: 10 abril 2020.

BRASIL. Lei 6.938, de 31 de agosto de 1981. Dispõe sobre a Política Nacional do Meio Ambiente, seus fins e mecanismos de formulação e aplicação, e dá outras providências. Brasília, 1981. Disponível em:< http://www.planalto.gov.br/ccivil_03/LEIS/L6938.htm>

COALISE. 4 Principais funções administrativas e por que precisamos delas. 18 fev. 2020. 
Disponível em: $<$ https://www.coalize.com.br/principais-funcoes-administrativas $>$ Acesso em: 15 abril 2020.

FENSTERSEIFER, Tiago. Direitos fundamentais e proteção ambiental: A dimensão ecológica da dignidade humana no marco jurídico-constitucional do Estado Socioambiental de Direito. Porto Alegre: Livraria do Advogado. 2008.

GIRARDI, Giovana; JANSEN, Roberta. Como nascem os lixões no Brasil. 14 abr, 2019. São Paulo e Rio de Janeiro. Uol - Estadão. Disponível em: $<$ https://noticias.uol.com.br/ultimasnoticias/agencia-estado/2019/04/14/como-nascem-os-lixoes-no-brasil.htm> Acesso em: $15 / 04 / 2020$.

IBGE - Instituto Brasileiro de Geografia e Estatística. Perfil dos Municípios Brasileiros: Saneamento Básico: Aspectos gerais da gestão da política de saneamento básico: 2017/IBGE, Coordenação de População e Indicadores Sociais - Rio de Janeiro: IBGE, 2018. 39p.

MILARÉ, Édis. Direito do Ambiente: a gestão ambiental em foco. 7. ed. rev., atual. e reformulada. São Paulo: RT, 2011.

MOTTA, Artur Francisco Mori Rodrigues. A dignidade da pessoa humana e sua definição. Âmbito Jurídico. São Paulo. 01 dez. 2013. Disponível em: <https://ambitojuridico.com.br/ cadernos/direitos-humanos/a-dignidade-da-pessoa-humana-e-sua-definicao/> Acesso em: 10 abril 2020.

RANGEL, Tauã Lima Verdan. O reconhecimento do direito ao saneamento ambiental pelo STJ: primeiras linhas da supremacia do mínimo existencial socioambiental em prol da dignidade da pessoa humana. 01 jul. 2016. Disponível em: <https://ambitojuridico.com.br/cadernos/ direito-constitucional/o-reconhecimento-do-direito-ao-saneamento-ambiental-pelo-stj-primeiraslinhas-da-supremacia-do-minimo-existencial-socioambiental-em-prol-da-dignidade-da-pessoahumana/> Acesso em: 10 abril 2020.

RECICLASAMPA. 41\% DO LIXO NO BRASIL VAI PARAR ONDE NÃO DEVERIA. 07 jul. 2019. Disponível em: $<$ https://www.reciclasampa.com.br/artigo/41-do-lixo-no-brasil-vai-pararonde-nao-deveria > Acesso em: 15 abril 2020.

SARLET, Ingo Wolfgang. Dignidade da Pessoa Humana e Direitos Fundamentais na Constituição Federal de 1988. Porto Alegre: Livraria do Advogado, 2001.

SNIS - Sistema Nacional de Informações Sobre Saneamento, Ministério de Desenvolvimento Regional. Manejo dos Resíduos Sólidos Urbanos - 2018. Disponível em: <http://www.snis.gov. br/painel-informacoes-saneamento-brasil/web/painel-residuos-solidos $>$. Acesso em 15 abril 2020 .

STEIGLEDER, Annelise Monteiro. Discricionariedade administrativa e dever de proteção do ambiente. Revista do Ministério Público do Estado do Rio Grande do Sul, n. 48, 2002.

VGRESÍDUOS. Passo a passo para o plano de Gestão de Resíduos Sólidos. 15 set. 2017. Belo Horizonte. Disponível em: < https://www.vgresiduos.com.br/blog/passo-a-passo-de-planos-paragerenciamento-dos-residuos-solidos/> Acesso em: 15 abril 2020

WWF, Fundo Mundial Para a Natureza (Antigo Word Wildlife Fund). Solucionar a Poluição Plástica: Transparência e Responsabilização. 04 mar. 2019. Gland, Suiça. Disponível em: $<$ https://www.wwf.org.br/?70222/Brasil-e-o-4-pais-do-mundo-que-mais-gera-lixo-plastico >. ISBN 978-2-940529-93-3. Acesso em 15 abril 2020.

Recebido em:05/06/2020

Aprovado em :15/06/2020 